\title{
Community Making: An Expansive View of Curriculum
}

\author{
Veronica Oguilve ${ }^{1}$, Wen Wen ${ }^{1}$, Em Bowen ${ }^{1}$, Yousra Abourehab $^{1}$, Amanda Bermudez $^{1}$, \\ Elizabeth Gaxiola ${ }^{1}$ and Jill Castek ${ }^{* 1}$
}

* Corresponding author

E-mail: jcastek@arizona,ed

1. University of Arizona, AZ, USA.

\section{Article Info}

Received: March 11, 2021

Revised: April 17, 2021

Accepted: May 23, 2021

\section{$10.46303 /$ icsr.2021.8}

\section{How to cite}

Oguilve, V., Wen, W., Bowen, E., Abourehab, Y., Bermudez, A., Gaxiola, E. \& Castek, J. (2021). Community Making: An Expansive View of Curriculum. Journal of Curriculum Studies Research, 3(1), 69-100.

https://doi.org/10.46303/icsr.2021.8

\section{Copyright license}

This is an Open Access article distributed under the terms of the Creative Commons Attribution 4.0 International license (CC BY 4.0).

\section{ABSTRACT}

Making as a term has gained attention in the educational field. It signals many different meanings to many different groups, yet is not clearly defined. This project's researchers refer to making as a term that bears social and cultural impact but with a broader more sociocultural association than definitions that center making in STEM learning. Using the theoretical lenses of critical relationality and embodiment, our research team position curriculum as a set of locally situated activities that are culturally, linguistically, socially, and politically influenced. We argue that curriculum emerges from embodied making experiences in specific interactions with learners and their communities. This study examines multiple ways of learning within and across seven community-based organizations who are engaged directly or indirectly in making activities that embedded literacy, STEM, peace, and the arts. Using online ethnography, the research team adopted a multiple realities perspective that positions curriculum as dynamic, flexible, and evolving based on the needs of a community, its ecosystems, and the wider environment. The research team explored making and curricula through a qualitative analysis of interviews with community organizers and learners. The findings provide thick descriptions of making activities which reconceptualize making and curriculum as living and responsive to community needs. Implications of this study expand and problematize the field's understanding of making, curriculum, and learning environments.

\section{KEYWORDS}

Making; maker spaces; community-based learning; living curriculum. 


\section{BACKGROUND}

\section{Researchers' Positionality}

The authors of this piece are scholars who study different facets of learning including literacy, second language acquisition, education psychology, and sociocultural studies. We share intersecting commitments to social justice, human rights, equity, and inclusion that honor the skills, practices, values, and brilliance of the people in communities who have long been systemically underserved. We are part of an educational movement that centers equity practices that require educators to be simultaneously conscientious of social realities and inequities and who actively work together toward systemic change. Individually, we represent Tucson, Arizona's Queer, Muslim, Latinx, International, Multilingual, Multicultural, Multiethnic, and Transnational community. Collectively, we are a research team that examines critical making cultures and practices with the explicit goal of disrupting exclusionary educational practices. We collectively honor the long-standing and historically situated cultures and making practices of systematically underserved people that have thrived in communities of color and low-income communities.

\section{Context}

This study's data was collected in Tucson, AZ. People and their connections with the land and the community are the heart of Tucson's vibrancy. The name of the city itself stems from the O'odham word Chukson meaning "spring at the foot at the black mountain" - the same black mountain that is visible to the west of the city, overlooking the once perennial and now dry Santa Cruz River. The land itself has a layered and complex history and is located on the traditional lands of the Tohono O'odham people and the Yaqui (Yoeme) people.

Tucson is a border city located in the southwest of the U.S. It is imbued with diverse ethnicities and culture. At the turn of the century, the warm and dry winter months once attracted people who suffered from lung illnesses. Tucson now attracts snowbirds (people who migrate with the seasons to warmer places) and encourages local Tucsonans to spend time outside.

Tucson has a unique geographical landscape surrounded by mountain ranges and beautified by the plants and animals that are unique to a desert landscape. It is a place known for breathtaking sunsets and historic architecture. It is a diverse community that brings together people from a spectrum of cultural, historical, and linguistic backgrounds.

Tucson is adjacent to the U.S./Mexican border. Despite Arizona's anti-immigration policies, the Tucson community goes against the grain in their support for migrants and refugees through efforts such as the We Reject Racism campaign (see Loyd, 2012). Gathering is important to those who live in Tucson. There are numerous heritage and cultural arts, sporting and music events such as Greek Festivals, Tucson Rodeo, El Tour de Tucson, Tucson Meet Yourself, Arizona Opera, and Mariachi and Folklorico dance presentations. Tucson's vibrant art scene includes 
museums, galleries, and hundreds of publicly available mesmeric public murals that dynamically change in response to public outcries and in celebration of the seasons.

\section{INTRODUCTION}

Tucson is home to several organizations that are known as makerspaces (e.g., spaces designed around hands-on arts, woodworking, digital engineering, and 3D printing). Activities that involve making are fundamental to the work of many of Tucson's community-based organizations. Any organization that has values that support collaboration and participatory processes, with creation and co-creation as shared values, can be seen as a making organization. Whether formally designated as a makerspace, or simply a space that involves aspects of making alongside its mission and core values, many community-based organizations are part of a vast maker community.

In this article, we argue that what constitutes a making organization is relationality-the connection among the participants who inhabit it. The organizations we studied bring together people of all ages and knowledge levels who make and create. In the sections that follow, we first examine making and its multiple definitions and then present our two research questions. Next, we explain our theoretical frameworks and highlight the methods used for conducting this online ethnography of community-based organizations. We go on to present our findings that suggest expressions of making are present in every part of a community, even in unexpected places like malls, places of worship, and the streets. Finally, we discuss our findings.

\section{Conceptualizing Making Across Definitions}

In the last decade, there has been a groundswell of interest in making (emphasis added by the authors to distinguish our more sociocultural view of making from other definitions that may be thought of as glittering generalities). Interest in making spans contexts such as schools, public spaces, crafting fairs, community groups, libraries, and museums. As such, making as a term has gained its own momentum yet at the same time is becoming more difficult to define clearly. Thus, we refer to making as a glittering generality of sorts - a term that bears social and cultural impact, connotes a particular meaning, but at the same time is non-specific.

Making has drawn much attention from educators and researchers alike since emerging studies acknowledge that making has the potential to support inquiry-driven, learner-centered, interdisciplinary learning (Moriwaki et al., 2012; Schlegel et al., 2019; Keune \& Peppler, 2019). Our analysis of the literature surfaced three ideas: 1 ) making is often related to materials and tools (Martin, 2015; Kafai et al., 2014; Halverson \& Sheridan, 2014); 2) making is a process of designing, tinkering, and modeling, through which people solve problems, develop multiliteracies, and create tangible or intangible products (Bevan et al., 2017; Martin et al., 2018; Vossoughi et al., 2013; Hira \& Hynes, 2016; Tucker-Raymond \& Gravel, 2019), and 3) making involves multiple relationships, including collaboration, mentorship, dialogue, and expertise exchange (Vossoughi \& Bevan, 2014; Hagerman et al, 2019; Hynes \& Hynes, 2018; 
Keune \& Peppler, 2017; Sheridan et al., 2014). Additional research has highlighted that making is a multifaceted way of learning that emphasizes creative, improvisational problem solving (Bevan, et al., 2015) and situates makerspaces as productive places to engage in potentially uncomfortable conversations (Tan \& Calabrese Barton, 2018). Makerspaces can be viewed as places of empowerment where participants seek to change and learn how different disciplines come together (Walan, 2021).

The majority of emerging studies associate making spaces and practices with STEM learning (Blikstein et al., 2017; Wohlwend et al., 2017). Few studies have documented the benefits of making at the community level or connect ways that making relates to personal experiences. These gaps in the literature point us toward examining making as a complex, layered, and nuanced endeavor.

Vossoughi et al., (2016) argue that narrow representations of making call for the need to foreground diversity and equity. This need prompted us to turn our attention toward adopting sociocultural approaches to examine the role of community in equity-oriented making practices (Green, 2017), to centralize the "inherent power and value of local knowledges, practices, and expertise" (Castek et al., 2019, p. 5), and to value scientific inquiry that is grounded in a personally, socially, and culturally constructed world (Olivares \& Tucker-Raymond, 2020).

Our research team conducted an online ethnography of community-based organizations in Tucson and documented all the contexts where making happens such as in arts-based organizations, Indigenous communities, libraries, museums, and personal spaces such as back yards and gardens. We narrowed our focus on seven community-based organizations to examine who was involved in these communities, what values and missions each organization held, what activities and programs occurred within these spaces, and how these activities intersected with what researchers have termed making.

An online ethnographic approach provided the means to look at Tucson systematically and comprehensively to characterize making within a specific community through the emergence of patterns and themes. We recognize that Tucson is a unique context with descriptive characteristics that are localized. We pushed against conventional views of making to argue that making is a human experience that is relevant to our lives, families, and cultures, and manifested in our goals, hopes, and dreams. Findings from this study offer an expanded definition of making and curriculum that casts a wide net of possibility for making as connection, making as service to the community, and peace making.

\section{Research Questions}

Insights about community practices and learning environments guided us to reconceptualize making and curriculum. In this descriptive online ethnographic study and through thick descriptions (Geertz, 1973), we addressed two research questions:

RQ1: How are Tucson organizations making?

RQ2: How is the Tucson community engaged in making? 
To address these questions, we problematized the narrow view of making as STEM learning and offer an expanded definition of making and maker spaces to illustrate how making is connected to individuals' lived experiences and communities. People's experiences in making are shaped by their knowledge, identities, and histories. Therefore, it was imperative to invite and embrace people's epistemologies as they relate to curriculum.

This study offers a descriptive lens to examine linguistically and culturally diverse community-based organizations, many of which are well-established. By looking at seven organizations' Facebook pages and websites, then interviewing leaders and learners from each organization, this study provides a descriptive view to address the research questions. We also discuss how embodied experiences with making may inform a socially just curriculum that builds from the lived experiences of people. The extension of this work will both expand and problematize the field's current understanding of literacy practices, learning environments, and cultural/artistic pursuits that serve to expand conceptualization of making.

\section{THEORETICAL FRAMEWORKS}

To address the goals of this study, we applied intersecting theoretical lenses. Both a critical relationality framework and an embodiment framework contextualized our research inquiry. The use of multiple frameworks was an intentional choice meant to expand and problematize the current understanding of the field in and around community making practices. Since the study's goals were dual, redefining making and reconceptualizing curriculum, so too were our theoretical frameworks. Both goals and theories express the duality of this inquiry. Critical relationality was a lens used to examine the experience of our community, while expressions of embodiment were a lens that surfaced detailed examples of individuals' lived experiences as they engaged in community making. Intersecting theoretical frameworks serve to represent a multiple realities perspective (Labbo \& Reinking, 1999) that collectively and synergistically disrupt traditional notions of making and by extension, also disrupt representations of curriculum.

\section{Critical Relationality}

Critical Relationality ( $C R$ ) was used as one lens through which we viewed making. As conceptualized by Olivares \& Tucker-Raymond (2020), CR is both theory and methodology for education research that centers the importance of deeply relational and humanistic commitments. CR emphasizes the power found in learning and the innate role of both the social and political in co-constructing learning.

CR has been previously applied to research in STEM communities (Olivares \& TuckerRaymond, 2020) however, this theory's application has expanded beyond STEM through diverse domains that are community centered. CR involves: 1) the examination of agency, structure, and connections to others as relational mediators of learning shaped by a variety of factors; and 
2) active attendance to those factors through disruption of conditions that function to oppress students of color through disregard for their experiential and out-of-school knowledge.

The CR perspective we adopted is rooted in various works such as critical race theory, decolonizing and de/postcolonial views, and methodology/pedagogy of the oppressed. Criticality and relationality are approached in these contexts as two parts of a whole (Martin \& Pirbhai-Illich, 2016). Criticality as applied to education and learning systems is the momentum of interrogation and questioning in an area of thought, while relationality offers a social and cultural lens through with to describe the connections between learners and the world they are a part of.

The tenets of CR suggest that all learning is political (e.g., Freire, 1970). Race and ethnicity, as political constructs, are operationalized as primary mechanisms for oppression in learning environments (Ladson-Billings \& Tate, 1995). Roles and relationships (e.g., between researchers and participants; between teachers and students) are powered and need to be interrogated in order to be reimagined. CR calls for flattening hierarchies and requires distributing authority for learning and knowing and asserts that identity is foundational to learning, and that it is dialogic and relational (e.g., de Peuter, 1998; Shotter, 1993). Finally, CR recognizes the need for social transformation of schooling and beyond offering praxis-oriented methodologies for professional work to examine teachingand learning interactions (Sandoval, 2005). CR, applied as a theoretical framework, can pave the way for transformative work that relies on connections between education, community, and society. The tenets of CR have been reimagined through our work to include embodiment.

\section{Embodiment}

Informal making and creating spaces are places of embodied, emergent, and relational phenomena. Education as a system approaches the body's relationship to space and place in various ways. O'Loughlin (2006) introduces the cognitive mind perspective, as a way to guide the body and the physical senses that the body experiences. When framing the self as embodied, we become a part of the environment taking shape within our educational context, which affects curricular choices and pedagogy. Therefore, an embodied curriculum considers people's lived experiences, with the focus on how people perceive and understand the world and environment around them.

The evolving concept of embodied curriculum enables researchers to view knowledge, reality, and curriculum in a more liberal way-- that is, as a mutual and continuous construction, co-construction, and reconstruction of what reality is and how it is experienced by people (Christodoulou, 2010). Although our work does not explicitly address curriculum in the way we often view it in educational contexts, we designed our study to note the ways community making experiences encompass many aspects of embodied curriculum and embodiment theory. The curriculum that emerges from embodied making experiences is unique to the situations, 
conversations and specific interactions had with learners (Powell \& Lajevic, 2011), suggesting that curricula be viewed as dynamic and fluid.

Embodiment is deeply rooted in the need to include not only a physical body as a part of the learning process but also the emotion and affect of that body into the learning process. By incorporating embodiment as theoretical framing, we engaged with collaborative environments that were co-created through learners being a part of their embodied place and space.

Figure 1 illustrates connections across this study's two theoretical frameworks. At the center, critical relationality radiates out with various connecting points to work in makerspaces and community networks, relationships to learners, and support for making and learning in the community. CR connections are established on the groundwork of embodiment nested in the spaces and places that are created for making work to happen.

Figure 1: Critical Relationality Expanded

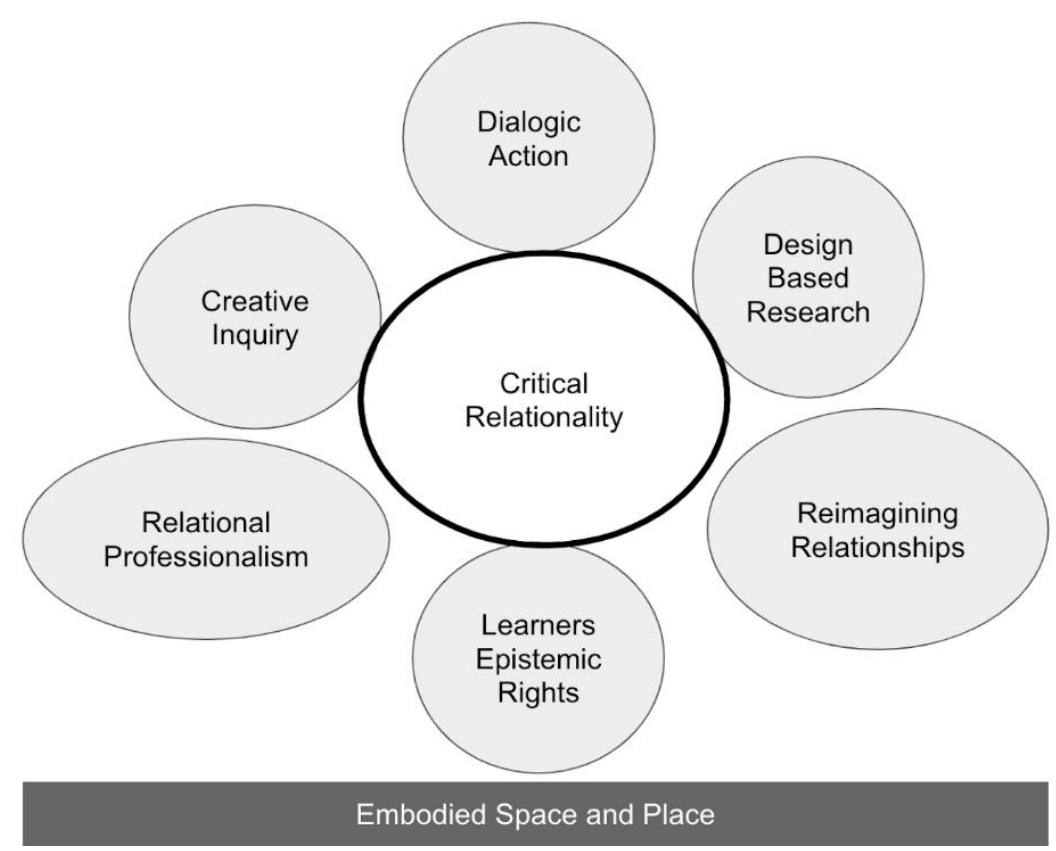

Note. The original tenets of critical relationality (Olivares \& Tucker-Raymond 2020) have been adapted to fit with the two theoretical frameworks used in this paper. Embodied space and place as it relates to the construct of embodiment (O'Loughlin, 2006).

\section{METHODS}

An ethnography developed from the field of anthropology and concentrates on understanding cultures and communities (Gerber et al., 2017). Conducting an ethnography typically requires the researcher (the ethnographer) to be actively present within a location. An online ethnography is also known as virtual ethnography, digital ethnography, or cyber ethnography and refers to ethnographic research conducted through the World Wide Web. Hine (2000) introduced virtual ethnography as developing out of ethnography and argued that cyberspace 
was "a place where people do things" (p. 21), in which we can "study just exactly what it is they do, and why, in their terms" (p. 21). Hine (2008) demonstrates that virtual spaces serve as field sites where researchers can study cultures and communities. We conducted an online ethnography of Tucson community groups because they each have a presence online that constitutes an important part of the organization's cultures and embodied practices.

\section{Sampling}

We used purposeful sampling (Merriam, 2009) to select the groups we studied. We reached out to different kinds of organizations who were involved in making in a variety of ways. We initially created a comprehensive list that we grouped into categories such as establishments in border regions, tribal areas, faith-based, art-based, and community-based organizations. We subsequently selected organizations based on personal connections we had with these groups. Selection led to the exploration of seven diverse community-based organizations. These spaces were grouped in three classifications: makerspaces, faith-based organizations, and cultural and community-based organizations. Table 1 details the specific organizations included in the analysis grouped by organization type.

Table 1: Community-based Organizations Grouped into Three Categories

Makerspaces

Xerocraft: A Community Hackerspace

Southern AZ Arts \& Culture Alliance (SACCA) Catalyst

Faith-based Organizations

Openspace Church: "The Graffiti Church"

Muslim Community Center

Community Based Organizations

Iskashitaa Refugee Network

La Galería Mitotera

BICAS (Bicycle Inter-Community Art and Salvage)

\section{Data Collection and Analysis}

Our initial observations offered insight about what took place in community-based organizations through images, write-ups, and first-hand accounts shared on public platforms such as the organization's website, Twitter, Facebook page, Instagram, and other social media. By exploring these spaces, it allowed us to generate field notes which assisted us in developing 
questions for interviews with leaders of the organizations. Recognizing the infeasibility of physical meetings due to the COVID 19 pandemic, interviews were conducted through email and Zoom video conferencing.

Semi-structured interviews with each organization's leadership and participants allowed us to explore the organization's efforts, purpose, and the participants' experiences. Additional data collection methods included analyses of web content, photographs, videos, archives of artwork, online communications, and the organizations' mission and vision statements. Questions posed to the community-based organization's directors included: In what ways does your organization connect with the community? How has making shifted in the COVID period? Questions that were posed to participants included: What connects you to this community/organization? What did the organization's activities and programs mean to you?

Thematic analysis (Braun \& Clarke, 2006) was used to identify patterns that were grouped and categorized to define and interpret the data. The analysis was derived from three components: 1) organizational mission and goals including how the organization started, 2) programming, and 3) outreach and participants' experiences.

Through the process of examining each community organizations' data, we collectively engaged in constructing and refining ideas through the process of listing, labeling, and grouping ideas to generate themes that represented shared characteristics. We applied collective interpretive power to deconstruct and reconstruct themes in light of our theoretical frameworks and collective data analysis (Gerber et al., 2017). To the extent possible, we examined data in a holistic way to stay true to the voice of our participants and organizations human centric values and missions. Once our themes and subthemes were identified, we located illustrative examples from our data. In the sections that follow, we illustrate how we grouped our findings into themes. We present those themes through participants' lived experience using their own words.

\section{FINDINGS}

This research began with very broad and with a general definition of making which guided our study of how Tucson organizations were making. Some organizations engaged in a more stereotypical version of making that included engineering, arts, or crafting while other organizations engaged in making that involved in upcycling materials for creative reuse, community beautification, and the design of self-care materials. Many making practices were culturally, spiritually, or politically influenced. Identifying themes and illustrative examples opened doors to documenting expanded ways that making occurs in a community.

\section{RQ1. How are Tucson Organizations Making?}

\section{Xerocraft Hackerspace}

Xerocraft Hackerspace is the most well-established makerspace in the Tucson community. It operates out of a big warehouse at the north edge of downtown. Xerocraft fits into the category of conventional makerspace-it provides people with a physical space to design, tinker, and 
produce creations using a variety of digital and manual tools. Xerocraft offers "Open Hacks" described as choice activities such as taking a tour, asking questions, using tools like a 3D printer, band saw, and sewing machines. Xerocraft also offers workshops for people to learn new skills from woodworking to metal casting and more.

Xerocraft welcomes people from all walks of life and requests a membership fee of $\$ 50$ a month for people who want extended access to the resources. Anyone who was interested could take classes, volunteer their time to facilitate and share expertise with others, or donate funds to support the organization's operations. The Xerocraft space combines both technical and artisanal approaches to making that involves designing, prototyping, and exchanging expertise (Bevan et al., 2017). Participants reported that they continually come back to Xerocraft because of the personal connections they forge together. While they work to create physical products, they also build friendships and sense of community.

\section{Catalyst Arts and Makerspace}

The Southern Arizona Arts \& Cultural Alliance (SAACA) Catalyst Arts and Makerspace is representative of a more typical Makerspace. Though its creation, location, and reception within the Tucson community differs from Xerocraft it can be defined a traditional makerspace.

Southern Arizona has long served as a hub for art and culture, yet creative and artistic individuals have found it difficult to connect and share their work, talents, and abilities with the broader community. SAACA, the organization behind the Catalyst Arts and Makerspace, formerly known as the Greater Oro Valley Arts Council, was created to help cultivate programming that uplifts local creatives and the culture of Tucson while supporting artists with direct ways to sell and monetize their work. SAACA has helped form innovative community festivals, cultural celebrations, and accessible arts enrichment programs.

The Catalyst Arts and Makerspace was established as an inspiring, innovative place where Tucsonans can connect through the shared experience of arts and culture. Catalyst was made possible by the partnership between SAACA and Brookfield Properties at Tucson Mall and in partnership with the Frank Lloyd Wright School of Architecture at Taliesin (SoAT). The goal of building a physical place was to bring diverse groups of people together to nurture shared learning and understanding, demonstrating the value of individuals and the power of community. The Catalyst Arts and Makerspace includes various areas that include a teaching kitchen, music and digital arts studio, education, inspiration and collaboration, arts and crafts studio, robotics and engineering lab, performance and event venue, and a co-working space for creatives.

\section{Bicycle Inter-Community Art \& Salvage (BICAS)}

BICAS is one of Tucson's more well-known and frequently visited non-profit community spaces. Its origin stems from an effort in the mid-1980s to support community members experiencing homelessness by providing them with reliable transportation-bicycles. Since then, BICAS has grown to encapsulate a physical workshop space, a work-trade program, art classes, women, trans, and femme (WTF) specific programming, and more. Shortly before the COVID 19 
pandemic, BICAS moved from their longtime north downtown basement workshop space, across the street from Xerocraft, to a different location located in Sugar Hill, a historically Black Tucson neighborhood. Because of the COVID 19 pandemic, their new workshop was temporarily closed to the public. Due to the increased socio-economic hardship on communities who are most vulnerable to global and community crisis, BICAS organizers and employees see their role as more important than ever and continue to offer discounted or free bike repair and aid to community members in need.

\section{La Galería Mitotera}

La Galería Mitotera is not only an art gallery but also space to build connection with the community, and for the community. It is very inclusive and welcomes the wider community in all events and programming. La Galería Mitotera is a community space that attracts diverse individuals and functions as a social hub connecting youth and adults.

The Galería supports individual identities by making cultural and traditional activities available to all. It is a place where community is built. The space functions as a platform for cross-community interaction both at the gallery and outside its physical building, such as in local schools, streets, neighborhoods, community gardens, and virtual spaces. Community-focused activities take the form of pláticas (talks), conviviencia (spending time), voice, togetherness, and cultivating creative expressions through making. Each of these activities and events enrich cultural life and serve to revive and uplift the Tucson community, especially in South Tucson where La Galería is located.

\section{The Open Space Church}

The Open Space Church, also known as the Graffiti Church, is part of the Lutheran denomination. What makes this church stand out is its use of graffiti to bring the community together. Participants make and share art, and in this way, create a space for making and community building. Its mission is to "encourage creativity and expression of faith through art, as well as giving art away and making it accessible to the community" (Open Space Church, 2018). The Open Space Church approaches this mission by welcoming and including everyone.

The Graffiti Church operates in different locations. Participants come from all over Tucson and the surrounding areas, even if it means hitchhiking or taking long bus rides to participate in the events in venues such as The Studio Space Tucson. There, people sketch and make small graffiti on canvas and on paper. Graffiti making happens in other places as well such as in Las Vegas, NV where Open Space Church artists paint commissioned graffiti art that often take the form of murals that are paid by individuals or organizations. At the church itself, participants paint on plywood outside the church and do faith-related commissioned art pieces in other churches.

\section{Muslim Community Center of Tucson}

The Muslim Community Center of Tucson (MCC) is a non-profit organization and Mosque that serves the Tucson community. Built in 2018, MCC serves immigrants and refugees from the Middle East, Africa, and Asia and is located in the northwest side of Tucson. On the MCC's 
website, it states that their mission is to "support justice, family values, honesty, truthfulness, mercy for the young, care for the old, and charity for the poor, upholding Islamic etiquettes and values; following the steps of Prophet Muhammad (peace be upon him)" (Muslim Community Center, n.d).

Before the COVID 19 pandemic, the MCC hosted two annual events that were cosponsored in partnership with other faith-based organizations such as St. Odillia Catholic Community, Tucson North Stake - The Church of Jesus Christ of Latter-day Saints, Temple Emanu-El, and Baha'i Faith of Oro Valley. Based on an exploration of the partnering organizations' social media pages and the MCC website, this partnership appears to be ongoing since 2015. Some of the annual events that happened before the MCC was built took place by rotation at different churches in Tucson. Though all these faiths are different, they shared a common goal -- the desire to come together in unity to build community understanding.

\section{Iskashitaa Refugee Network}

Iskashitaa Refugee Network is a non-profit organization that has worked with Tucson's refugee community and beyond for over 17 years. They partner with local gardens, farms, and other growing operations as well as local community members to locate harvestable fruits and vegetables. The intention of the network was two-fold: to divert food waste and to integrate refugees into the Tucson community while also familiarizing them with the geography and culture. Refugee community members, as of now, are representative of 30 different ethnic groups. The mission has grown to include the goals of increasing the local food literacy of the wider community and helping refugee families build on skills such as entrepreneurship and leadership.

According to the network's website, the name of the organization itself is a Somali dialect Maay Maay word that means "working cooperatively together." One way the spirit of the name "Iskashitaa" is represented is in the fact that participants and volunteers are synonymous with one another-there are many ways to engage the network. If someone has a fruit tree in their backyard, for example, they can call Iskashitaa and they will come and harvest the fruits from that tree. This diverts fresh food back into the community. Iskashitaa may alternatively process the fruit in a preserved form. Though the pandemic shifted programming and participation, cooking lessons are still being held online and outdoor activities - food harvesting, gleaning, and garden tending have been able to continue.

\section{Research Question 1: A Summary}

While some of the community-based organizations described might be seen as typical makerspaces involved in STEM making, the work of taking place in Tucson community organizations calls for an expanded view of making. This expanded view considers making not as a new trend or fad, or limited to any particular type of space, organization, or method but rather as a series of community practices. 


\section{RQ2: How is the Tucson Community Engaged in Making?}

Often the literature base that describes making considers making activities to be synonymous with collaboration, design, innovation, and more. We found that considering the function the making serves, together with impetus for being engaged in making, offered new insights and a more locally specific notion of making. Our analysis revealed three major themes: making-asconnection, making as a service to the community, and making as peace making. Table 2 illustrates the themes and subthemes and their definitions. A thorough description and illustrative examples follow.

\section{Theme 1: Making as Connection}

A feature of making in the Tucson community was making as an expression of connection. Making connections was both a purpose connected to the organizations' mission as well as an outgrowth of the organizations' programming. Table 1 includes definitions of each subcategory of making-as-connection: 1) inclusion, 2) art, 3) safe spaces, and 4) fulfilling essential needs. Inclusion. All seven Tucson community-based organizations engaged in making as a way to create connections in the community. Connection is manifested in many ways such as valuing refugee and immigrant life, assets, and funds of knowledge (González et al., 2005). Moreover, organizations engaged in art as creative expression, as an avenue towards bridge-building. Each organization was deliberate in the cultivation of "safe spaces" for systemically underserved community members. Organizations described multiple ways of connecting community members together for the purposes of fulfilling human needs (Vélez-lbáñez \& Greenberg, 1992). All of the organizations, whether they were involved with making artifacts or completing a material goal, engaged in making-as-connection.

Refugees and immigrants often arrive in the United States burdened with feelings of alienation and anxiety due to the linguistic and cultural barriers. In order to be part of a community, individuals need to cope and gain a sense of belonging in the new home, but this comes with challenges. Community-based spaces provide making activities and making events that promote connections among people. The Muslim Community Center of Tucson and the Iskashitaa Refugee Network support refugees and immigrants in connecting through making. Moreover, the lived experiences of refugees and immigrants are appreciated and valued by these organizations and these values are personified through making.

One example of making-as-connection occurring at the MCC is the "Family Cultural and Game Night" held once monthly (pre-COVID). There are many members in the MCC community from diverse Islamic cultures, including immigrants and refugees from the Middle East and North African region and Asia. They come to game night to share their cultures, dressing in their traditional attires, and bringing authentic dishes that represent their home country. Some participants stated, "Together we pray, eat, play, and have fun while making new friends" (Muslim Community Center, n.d.). Building relationships and nurturing through sharing food and play are initial steps for making connections for the inclusion of all people. 
According to an interview with the volunteer manager, Iskashitaa intentionally draws on the vibrant and rich knowledge base of refugee families and individuals when deciding how best to use gleaned local food, some of which are not stereotypically used in Tucson kitchens like carob pods. One example is their use of the multitude of left over and typically wasted pumpkins each fall to make Afghani Kadu. In this making activity, Afghani refugee community members are the culinary and cultural experts and insiders, and their knowledge is directly benefiting Tucsonans and refugee community members from other ethnic groups who might not otherwise know how to prepare the Kadu. The exchanging of multiple forms of how-to information in the making activity-how to locate the pumpkins to be diverted from waste, how to process the whole pumpkin, and how to prepare the Kadu -requires input from knowledge holders across the wider community. Connection is essential to the ultimate goal of making the food products and is simultaneously a by-product of the making activity itself.

Art. We identified making-as-connection through the wide use of art and artistic expression as an avenue towards bridge-building. Artistic making in community spaces offers opportunities for participants to create and connect across identities, ages, and experiences. The Southern Arizona Arts \& Cultural Alliance's (SAACA) Catalyst Collaborative Arts \& Maker Space was created with this exact purpose in mind. According to its website, the space "provides a first-of-its kind gathering and learning space for our community. Each square foot of this space has been designed with flexibility, adaptability, and accessibility in mind" (SAACA, n.d.).

The Open Church, also known as the Graffiti Church, is popular among community members. Attendees take local transportation from all over the city to meet, connect, and create in the space. The Graffiti Church is a self-organized space where graffiti artists become mentors and help attendees develop skills in planning, sketching, drawing, and painting. As a participant states, graffiti artists are experts in drawing, not just in painting with spray. They also said that the art of learning to do graffiti starts with using a pen.

Another participant said that the process of making in the Open Space Church has helped them explore their boundaries and discover the artist within. In the space, participants are able to express themselves freely and as such, the graffiti themes are not limited to images related to religion. Participants paint themes related to their own identities (Bowen, 2013), experiences, and connections to Tucson. In sharing connections with others, they are also actively bridgebuilding across their different backgrounds and experiences.

La Galería Mitotera serves as a gathering space where making is deeply connected to connections with culture and traditional practices, specifically those of the Latinx and Indigenous communities. For example, participants learned how to make atole (a Mexican traditional hot beverage), engaged in piñata making, and painted iconic Latinx recording artists. A sense of connectedness is also fostered in storytelling activities led by adult Chicanx authors for youth participants. These activities function as a bridge and enable community members, both youth and adults, to dialogue, be heard, and come together to beautify neighborhoods through artistic expressions in the form of mural art. Not only is the end product of making 
important but also the process of making. La Galería collaborates with local partners to bring awareness to issues that encircle our communities. Collectively, participants engage in grassrooted activism and artivism as seen through art installations. As such they acknowledge, and honor migrant remains found in our desert.

Safe Spaces. Making-as-connection involves the creation and maintenance of "safe spaces" for systemically underserved community members. Spaces, like bodies, are not neutral and must be seen in relation to social structures, culture, discourses, and situated historically and spatially (Olivares \& Tucker-Raymond, 2020). That being said, if the intention of an organization is to cultivate connections in an equitable way, "safe-spaces" are a necessity as they acknowledge power dynamics on a micro and macro level.

The Graffiti Church itself functions as a "safe space" on multiple levels. First, it is a gathering point for people experiencing homelessness from many different cultural, ethnic, and racial backgrounds. Second, graffiti itself is often seen as being synonymous with criminal behavior, but in the Church artists and participants are encouraged to use graffiti freely to express themselves. Pre-COVID 19, the church hosted several events aimed at cultivating a welcoming and often family-friendly space. For example, an open-to-the-public pizza art night where people learn to draw and paint and make their own art or activities like "Wet Paint" where artists, like Neoglyphix-an all-Indigenous graffiti crew-made graffiti live (Open Space Church, 2018).

BICAS, considers themselves as both a makerspace and STEAM organization and as such regularly partners with other organizations including Xerocraft. Forward-facing materials cite the reality that bike maintenance is a stereotypically "(cis) male-dominated area" and for that reason BICAS created specific bicycle maintenance and workshop times for women, trans*, and femme (WTF) identified community members, so they could build confidence and skills without pressure or intimidation. Pre-COVID19, these designated workshop times happened on Mondays at 3-7pm and expanded into other social events such as WTF movie nights and community bike rides. During the pandemic, much of this programming has been suspended though community members still connect through the WTF Facebook page.

La Galería Mitotera's location in South Tucson ensures that their space is accessible to our community. It is a very inclusive space, hosting initiatives that are open to diverse backgrounds and ages. Examples of activities provide space for the sharing of young artist's creations, hosting cafecitos (coffee get togethers) with the cast of a play regarding gang life dramas and gender queer identities, hosting lowrider shows, and curating art exhibits that featured sixteen Indigenous artists who represented seven tribal communities from Tucson to Oklahoma. The gallery creates a social space supportive of wellbeing, openness, and accessibility - a much needed and welcomed resource for the Tucson community.

Fulfilling Essential Needs. Several organizations participated in making activities as a way to fulfill essential needs of those living in Tucson. Xerocraft, a well-established organization launched into action in response to COVID 19. The sudden increase in COVID cases and shortage 
of PPE put Tucson health workers at risk and in need. By the end of May 2020, Xerocraft had created and distributed personal protection equipment (PPE) and supplied them to local health care providers. Donated equipment included 230,395 surgical masks, 27,232 N95 masks, 317,175 nitrile gloves, 19,986 face shields, 3,802 goggles, 9,782 isolation gowns, and 673 handmade cloth face masks (Xerocraft, n.d.). By fulfilling this need, Xerocraft was able to pay unemployed community members 20 dollars an hour for their work creating PPE.

Every year, fruit trees in Tucsonan backyards and on business properties produce fresh, local food and Iskashitaa Refugee Network is able to step in and ensure that sustainable food source such as fruit trees, community gardens, or previously overlooked food sources are not wasted but instead are re-routed back to both the refugee and the wider communities. In performing this sustainability-minded task and need, Iskashitaa also connects refugee families with the community to practice English with, gain familiarity with Tucson, and acquire employment-oriented skills.

BICAS, similarly, exists to ensure that community members, including those who are experiencing homelessness have access to sustainable, safe, and effective transportation in the form of bicycles. Even in the pandemic, they have continued to offer free or heavily discounted services as much as possible. BICAS recognized an increased need for access to transportation in times of socio-economic hardship.

Pre-COVID 19, the MCC invited community organizations to use the space for fulfilling an essential need. An example of this is the Annual Fall Festival which was mainly a fundraiser for refugees and organized by Noor Women's Association. The event was managed by interfaith women who are all volunteers. This association is a charity located in Tucson that helps assist new refugee community members, especially widows and single parents, with transitioning to life in the U.S. (Muslim Community Center of Tucson, 2019).

\section{Theme 2: Making as Service to the Community}

A feature of making in the Tucson community was making in direct response to the needs of the community. This need-based approach not only contributed long-term community buy-in over many years, but also ensured that the organizations could successfully shift their programming when faced with the COVID-19 pandemic. In short, Tucson community organizations' making practices were committed to serving the wider Tucson community in essential ways - such as food security, health and safety, transportation, employment, and connection. Through their commitment, organizations experienced both longevity and resilience. Table 2 includes definitions of each of these subcategories of making-as-service to the community including four specific dimensions: 1) food security, 2) health and safety, 3) employment, and 4) relations/relationships.

Food Security. MCC's public outreach goals led them to create and host public events with their partners from multiple faith groups. One example of a public event is the Packathon. Packathon is an annual event they organize to pack food for people experiencing houselessness in Tucson. This event is open to the public and not just people from faith groups. Their goal is to pack 
50,000 meals every year. The "Tucson Interfaith Packathon" Facebook page (Tucson Interfaith Packathon, 2018) indicates that the event took place at different churches, and it seems that the MCC hosted this event in the past three consecutive years 2017, 2018, and 2019. All people and all ages are welcome to participate in this event.

Iskashitaa, engages in making as a service to the community in the realm of food security. Through their previously in-person, and now online cooking and food preservation classes, Tucsonans can learn how to preserve and process their own food. Additionally, refugee families and individuals are connected to local, sustainable, and culturally relevant food sources and methods of cultivating food.

At the Graffiti Church, during the Open Art Nights, also known as "Pizza Paint," many people from the community who are houseless or in a need for food are invited to create art while having pizza and sharing with other people. Through this event, participants get connected with two fundamental human needs-social relationships and sustenance. Even when this small-scale action of nurturing may be overlooked, the Office of the High Commissioner for Human Rights (OHCHR, n.d.) emphasizes the need for an adequate standard of living for every person. The Graffiti Church makes food accessible and provides nutrition opportunities for those who would not have them otherwise.

La Galería Mitotera hosted food drives and has delivered food boxes to local families. They have been an information resource for the community, for example, maps that show information as to where to obtain food boxes as well as grocery stores which list special shopping hours due to the pandemic, dedicated to seniors and vulnerable populations.

Health and Safety. Iskashitaa's emphasis on both fresh and local produce as a basis for food sustainability and healthy produce preservation techniques reflects making that addresses health and safety needs. Xerocraft's recent effort to create PPE for local health care workers also mirrors this emphasis. While Xerocraft was not open for the public during the COVID 19 crisis, they were able to switch gears to provide an important service in response to the pandemic. Beginning in March 2020, Xerocraft initiated pandemic response actions. They called for medical gowns for medical personnel in the community. Xerocraft provided online tutorials, criteria, and instructions to demonstrate how to turn a twin-sized bed sheet into a washable hospital gown. They also set up a face shield manufacturing line and supplied the Pima County Health Department with over 32,000 face shields (Xerocraft, n.d.).

Employment. Prior to the pandemic, Xerocraft offered apprenticeships where participants could acquire skills in welding, mechanics, designing, and other engineering practices. These skills are transportable to multiple contexts and may also support future workforce possibilities, which equally benefited the community. During the pandemic, Xerocraft employed community members who were unemployed at a rate of $\$ 20$ an hour, a living wage in Tucson. Not only did workers come away with income, but they also acquired technical skills needed to produce lifesaving equipment. 
Iskashitaa's programming, while not directly tied to finding employment for refugees, is linked to improving skills needed for employment including but not limited to, entrepreneurial and leadership skills, "applied English language practice," and networking opportunities (Iskashitaa Refugee Network, n.d.). Linked closely to employment as an essential need is transportation-which has been BICAS's primary mission since its inception. An international graduate student at the University of Arizona who relies on her bicycle for transportation was a frequent visitor of the BICAS workshop pre-COVID. While she has not needed any essential repairs on her bike as of late, she donated in Spring 2020 saying that "it is so important to me that the space continues to exist after the pandemic".

Art created by both emergent and expert artists served a form of income for the Graffiti Church. Community members purchased mini paintings during events where the Church presented artists' pieces of work. Artists also created commissioned murals in churches and other spaces. Both the art sold to the community and the commissioned art pieces were paid in a donation-based arrangement. The money earned was equally shared between the church and the emergent or expert artists. This approach to entrepreneurship was doubly good for the artists. Not only do they earn a portion of the donation, but they also gain more exposure and are able to widely network, furthering opportunities for future paid work. The Graffiti Church also makes their prints available in local tattoo shops. Relationships that were built between the participants and the organizations were both meaningful and economically beneficial (Olivares \& Tucker-Raymond, 2020).

Relations/relationships. Given the nature of making as collaborative and social, every organization engaged in practices that directly or indirectly led to the cultivation of social relationships. Some organizations like Iskashitaa, prioritize relationship building as a key pathway towards achieving its central mission. Other organizations, such as The Open Space Church, elevated the status of graffiti and celabratted community members for whom this art form was an important form of expression. Participants who engaged with these organizations did so to have their social and connective needs met alongside other making oriented goals.

The Muslim Community Center (MCC) engaged in making activities where the activity itself was a conduit for connecting people from different faith communities and connecting those faith communities to the larger community. Making connections and forming relationships requires the strength to be comfortable facing uncomfortable conversations. For instance, the MCC can be considered one of many "[...] productive spaces for youth to engage in potentially uncomfortable conversations necessary to create authentic making cultures in their communities" (Tan \& Calabrese Barton, 2018, p.59). One example of these "uncomfortable conversations" surfaced in an interview where an interfaith conversation asked about Muslim women's head covering or 'hijab' and why they "dress modestly."

Dialogic interaction gave rise to new insights. Women from Islamic faith groups can be regarded as front liners as their head coverings communicate their faith to the public, and this positions them at risk for racial discrimination. The peace making conversations that emerged 
in this space helped participants understand personal choices and provided greater understanding, cooperation, and opportunities for transformation in learning about others and the world at large.

In the Graffiti Church, participants appeared to become more empathetic and connected because of their physical presence in the church's shared space. Drawing on embodiment theories, the body is not just a biological entity, but reflects what is external to self, including spatial experiences, meanings, understandings of the world, and individuals' connections to it (Christodoulou, 2010). These external elements include social structures, cultural expressions, and discourses, all of which have a connection to lived experiences. Lived experiences are unique to each individual, for example, a brown body that is engaged in making is not the same as a white body engaged in the same act because of different lived experiences.

A participant of the church mentioned an event in which he, a white man, and a Native American artist were painting graffiti in the church space. A participant reported that a neighbor called the police and complained about "a drunken Indian being loud and causing trouble." The participant who narrated the event took a protective stance and understood his privilege. He explained to the police that the expressive graffiti they were making was legal and on their own property. Incidents like this illustrate forms of implicit racism that are present in society. Community making surfaces these stances and seeks to change attitudes and experiences. Not everybody is aware of their own biases because these groups do not usually interact. Graffiti making created a contact zone that allowed these attitudes to be acknowledged, confronted, and discussed making space for change.

According to BICAS's Youth Program Director, BICAS is one of the few places in Tucson where people from very different races, classes, ages, genders, gender identities, and orientations, regularly share space-from Southside viejitas, to fancy roadies looking for good deals, to groups of teens who are earning bikes. On their busiest day pre-COVID, usually a Saturday, as many as 80-100 people would visit the space. As the director stated, "BICAS has always been in the business of more than just bikes..." and this is evident to us as we consider how many different Tucsonans go there, and have been going there, to acquire skills, make bike repairs, and forge social connections with like-minded people.

Iskashitaa, by nature of its mission, is committed to connecting refugee and asylum seekers to the Tucson community as well as connecting local food growing operations and food sources to a network of volunteers. As Iskashitaa's name implies "working cooperatively together," the work of this organization is deeply rooted in sustainability practices that creates a bond among different members of the community.

In researching La Galería Mitotera, for example, a participant who attended an event on positivity pride shared the personal relationships that are formed through making. Attending the Juan Gabriel Paint Nite was tied to making cultura in various ways. An anonymous participant shared: 
As a queer Chicana, Juan Gabriel was a very important icon for me while growing up. I grew up in Ciudad Juárez, so in many ways Juan Gabriel was centered into my childhood -from passing by his house, to listening to my father play his music, and later to singing his music with my mother, his presence has always been in my life. After making my art, I felt reenergized to continue to work hard towards a representation of queer people of color.

Illustrated in this quote is the resonate idea that La Galería Mitotera's programming has encouraged participants to build relationships and make human connections, drawing people together with shared social justice perspectives through culture and language.

\section{Theme 3: Peace Making}

Peace making can be considered a novel facet of making that emerged from this research. Like our participants, we view peace making not as resolving a conflict between multiple parties, but rather evolving from a humanistic viewpoint in which individuals come together and discover shared feelings that are expressed in interdependent ways. To advance this analysis, peace making was defined with two dimensions: 1) fellowship and 2) enrichment. Table 1 includes definitions of each of these subcategories of peace making.

Our analysis suggests that making creates the conditions of fellowship and enrichment and offers these connections to the larger Tucson community through peace. The making that transpires among and between people, beyond the artifacts that are created, are expressions of peace, unity, and fellowship.

The two dimensions associated with peace making, fellowship and enrichment, employ dialogue as a tool for connection and are crucial for making peace and envisioning the distinct and unique experiences and knowledge that diverse people possess. While engaged in making, everyone is part of a collective where the shared goal is embodied in unity, peace, and dialogue. Dialogue requires engaging in uncomfortable conversations and leads to a transformation personally for oneself and collectively for the community. An important outcome of making can be demonstrated in coming to understand and respect one another regardless of different viewpoints, perspectives, and experiences.

Fellowship. Some Tucson faith-based organizations organize events and field trips to other places of worship two or three times annually (pre-COVID). The Muslim Community Center (MCC) is one of those transnational spaces that is open to cultures, languages, and multiple faiths. Pre COVID, learners from multi-faith groups came together and engaged in conversations. In an interview with a participant from MCC, talked about making friends. They stated: "We talk about our similarities and differences, [we talk about] God and what they believe in and the holidays they celebrate. We talk about our prophets, and we talk about our viewpoints." According to this participant, they appreciated and respected their differences with friends from other faith groups. One participant shared what kept them coming back to this community was making friends. The enriching feeling of friendship these dialogues offered youth new connections and strong connections across multiple faith groups. One young 
participant stated, "I have heard about their religions, from someone my age, yeah!" This quote suggested that dialogic interaction encouraged more than friendship, but as a form of "sisterhood." Fellowship was identified as a product of peace making that emerged from open dialogue between multi-faith youth groups.

The Graffiti Church connects people from different backgrounds who use art for selfexpression and these connections led to the development of cordial relationships. Participants developed activities that revolved around visual art, dance, music, and body art. These networked interactions happen between people of different ethnicities, cultural groups, and in different languages. For example, during Paint Nights, various DJs (e.g., DJ Alfuego) and music artists from different genres (e.g., Method to Madnez, Las Florecitas Rockcheras) were featured, providing access to their culture. In this space, people are allowed to express themselves in the way they feel comfortable, which can open new doors to being accepting of other people's idiolects, even if it includes vocabulary that is not usually used in a church setting. The Graffiti Church is also different from other churches in Tucson which are divided by cultural backgrounds. At the Graffiti Church, everyone appreciates their differences, even when they have very different backgrounds.

La Galería Mitotera has collaborated with community members to beautify and make the neighborhoods safer. For example, they have led mural projects to paint intersections near schools to create safer school crossings. Multigenerational activities have included school staff, students, families, and neighbors engaged in painting murals with symbols that illustrate rejoicing and embracing the school and community. Symbols include suns, sunsets, cacti, and Aztec mythology. The embodiment of creative practices through art making creates spaces for learning and for liberating the mind, to allow participants opportunities to dream and to heal. La Galería Mitotera hosted a community discussion on gentrification and its impact on South Tucson. These platforms of formal and informal dialogue serve as catalysts for positive social change. Collectively, the community is connecting making with participatory culture and transformation through learning and creative engagement. Social injustices can only be challenged through praxis (engaging and action), which is apparent in the work of the La Galería in collaboration with our community members.

Enrichment. Enrichment for peace making happens in many activities that promote ways to nurture the body, soul, and mind. From the data we gathered, we analyzed how seven organizations organized their events and how enrichment was happening in multiple spaces. Images on the MCC Facebook page (Muslim Community Center, n.d.) represented multi-faith youth groups making cupcakes. These images exemplify the collective effort in reading directions on the packaging, mixing the ingredients, and pouring them in cupcake liners. These making practices are rooted from fellowship and enrichment for making peace. Therefore, the product of cupcake making is an artifact that is a form of breaking bread. Baking together acts as a metaphor for peace making where everyone thinks beyond the "self." In other words, learners' diverse identities are part of a collaborative effort that is tied to their community. Thus, 
these faith-based organizations become transnational spaces that nurture belonging across cultures, languages, and faiths.

In the Open Space Church, participants are breaking down barriers, and reimagining relationships (Olivares \& Tucker-Raymond, 2020) both physical and social, and engaging with different people. In fact, a learner, who is a traditional member of the church and calls themselves "square", mentions that in these events, they encounter people who they would never come across regularly. They have found that open and regular interactions have changed their mind and now they are comfortable around people who come from very different paths and have different experiences. They said this experience pushed them out of their comfort zone. Likewise, graffiti artists have forged new pathways of street credentials (street cred) that allows them to participate in different spaces where artists hang out. For example, there is a participant who has gained access into artistic places in the community that are not easily accessible to others. Artists and other community members, like houseless people, and those from different backgrounds have their space in the church, too. The church has become a space of belonging that brings people together, outside of religious purposes.

Nurturing the mind is encapsulated in community makerspaces like SACCA Catalyst Studios. This community makerspace offers access to robotics and various technologies for expanding STEM literacy, however it is the hands-on engagement of learners in the space that offers transformational opportunities. Catalyst in the past has offered workshops in robotics and coding, opening the social space to testing robotics from Bit Buckets, a community-based middle and high-school STEM team that competes in robotics competitions and other technical challenges. During the COVID-19 pandemic, various means of online outreach have been used to keep access to learning open. Bringing together learners from various disciplines and connecting goals in areas in the arts and sciences builds an important interdisciplinary bridge. Collaborations illustrate the benefits of forming new networks and engagement across the Tucson community. Thus, SACCA Catalyst has become a space for STEM enrichment where peace making is happening by building connections among and between arts and sciences.

La Galería Mitotera has hosted many events, including in person and virtual self-care workshops. These events include virtual mindful movement and meditation, yoga classes, clay art, and lip balm making. The goal of these events has been to promote the wellbeing of local community members, even in these unprecedented pandemic times. Additionally, they have also hosted fundraisers for the community. For example, they displayed a Christmas wish list and received thirty donations which they gifted to South Tucson youth. During a paint night fundraiser of the Día de los Muertos (Day of the Dead) they raised $\$ 450$ for The Colibri Center for Human Rights to provide twenty-two DNA kits to families hoping to identify remains of loved ones lost in our desert. 
Table 2: Research Question Two's Themes, Subthemes, and Definitions

\begin{tabular}{|c|c|c|}
\hline Theme & Subtheme & Definition \\
\hline \multirow{4}{*}{$\begin{array}{l}\text { Making as } \\
\text { Connection }\end{array}$} & Inclusion & valuing refugee and immigrant life funds of knowledge \\
\hline & Art & engaging art as an avenue towards bridge-building \\
\hline & Safe Spaces & $\begin{array}{l}\text { the cultivation of safe spaces for systemically underserved } \\
\text { community members }\end{array}$ \\
\hline & $\begin{array}{l}\text { Fulfilling } \\
\text { Essential Needs }\end{array}$ & $\begin{array}{l}\text { connecting community members together for the purposes of } \\
\text { fulfilling essential needs such as transportation, food, internet } \\
\text { access, housing, health and mental well-being }\end{array}$ \\
\hline \multirow[t]{4}{*}{$\begin{array}{l}\text { Making as Service } \\
\text { to the Community }\end{array}$} & Food Security & $\begin{array}{l}\text { making food sources available to the community through food } \\
\text { picking, food packaging, helping to meet dietary needs for a } \\
\text { productive and healthy lifestyle }\end{array}$ \\
\hline & $\begin{array}{l}\text { Health and } \\
\text { Safety }\end{array}$ & $\begin{array}{l}\text { producing sustainable and healthy foods through food } \\
\text { preservation, creating PPE to keep the community safe from the } \\
\text { spread of infection, health testing, and keeping in mind the needs } \\
\text { of a healthy community }\end{array}$ \\
\hline & Employment & $\begin{array}{l}\text { hiring and paying people for their work, helping to train people } \\
\text { for future jobs and careers; gaining hands on skills and knowledge } \\
\text { for new opportunities }\end{array}$ \\
\hline & $\begin{array}{l}\text { Relations \& } \\
\text { Relationships }\end{array}$ & $\begin{array}{l}\text { being connected through respect, transformative human } \\
\text { connections that are authentic and sustained; activities that draw } \\
\text { people together around common goals }\end{array}$ \\
\hline \multirow[t]{2}{*}{ Peace Making } & Fellowship & $\begin{array}{l}\text { friendly association especially with people who share one's } \\
\text { interest, expressing appreciation to one another and being part of } \\
\text { one community }\end{array}$ \\
\hline & Enrichment & $\begin{array}{l}\text { mindfulness and freedom embodied through nurturing to the } \\
\text { body, mind and soul in the making process }\end{array}$ \\
\hline
\end{tabular}

\section{Research Question 2: A Summary}

The Tucson community engages in making practices in various ways. The descriptive analysis and three themes identified in Table 2 illustrate making as multidimensional and multifaceted. The first theme, making as connection to the community was identified as a central theme throughout our analysis. Sub-themes describe how organizations serve the community, illustrating that participants' funds of knowledge (González et al., 2005) and funds of identity (Subero,Vujasinović, Esteban-Guitart, 2017) were valued. Funds of knowledge and funds of identity are vital part of peoples' lived experiences that shape knowledge construction and meaning making. Acknowledging these lived experiences, cultures, languages, and histories of 
communities highlight their presence and knowledge resources. Connection encouraged organizations to fulfill essential needs and cultivated "safe spaces" for self-expression through arts and community practices. The second theme described making as service to the community. Sub-themes describe how making activities assisted the community in gathering resources for health, safety, food security, and employment. In the process, making provided the contexts for sustaining authentic connections and relationships. Finally, peace making described the subthemes of fellowship and enrichment. Peace making expands making by centering dialogue and nurturing as parts of community programming. Fellowship and enrichment were reflected in the embodied processes that included sharing common interests, making friends and nurturing the body, mind, and soul.

\section{DISCUSSION}

This online ethnography of community-based organizations in Tucson serves to document the extensive and multi-dimensional types of making that take place within a single community. Making in Tucson is rich in community practices, and it revolves around connecting, providing service to the community, and peace making. This study demonstrates that an expanded definition of making is necessary to encompass all the making practices that occurred in a community. These practices extend beyond traditional notions of making that usually reflect STEM learning. Factors such as populations served, experiences of participants and organizers, how making relates to community involvement, and network building also need to be considered. This study challenges the notion of curriculum as pre-planned, structured, subjectdriven that is commonly used in formal educational environments. Researchers suggest the extension of this work will both expand and problematize the field's current understanding of making, curriculum, and learning environments.

\section{Reconceptualization of Making}

To define making in an expanded way, it is necessary to explore what activities communities and their diverse members are performing. We examined community-based organizations to learn about their missions and how they pursue goals and design their programming to better understand why they engage in these activities, and how these activities bring people together. We have come to understand making as a dynamic concept, illustrated in the examples offered throughout this online ethnographic study. We have come to view making as explicitly driven by community needs. For example, Xerocraft, which could be mistakenly categorized just as another makerspace for people to work on their individual projects as a new kind of community space. Through collaborative community efforts, participants designed, prototyped, and exchanged expertise among diverse people from all over Tucson to serve community-specific needs. Participants made PPE in the thousands during the COVID19 pandemic to ensure the well-being of the community. This exemplifies how dynamic and collaborative the knowledge creation process is, and how the organization rallied together to serve the community's needs. 
Making activities include facets of both learning and community development. For example, members of the Ishkashitaa Refuge Network work on diverting food waste and learning about the geography of Tucson and its diverse people and cultures. At the same time, Ishkashitaa worked to develop a community-based sense of belonging to Tucson, its land, and resources. The Muslim Community Center of Tucson, composed of different religious and ethnic groups, was driven toward community development by fellowship and enrichment. Across multiple organizations, participants came together regularly in a common space to support other community members using food, identity, graffiti, food packing, art-making, social events, and most importantly use dialogue to understand and appreciate each other.

Art is an important form of making that includes creative thinking and self-expression, design and innovation, and critical thinking that can be employed to tackle real-life, complex problems. La Galería Mitotera, The Graffiti Church, and SACCA Catalyst are open and welcoming art-based organizations that encourage the development of community building, empowering their members and participants.

Each organization described in this study is unique with its own experiences, history, mission, location, participants, and relationships to the community. It is these specific aspects of context that drive making. Making in the Tucson community may be unique and different from making in other locations; however, this localized view underscores the importance of individuals' experiences, stories, and connections with their community. Therefore, these findings offer a renewed view of responsive curriculum, one that is cultivated from the community's specific, unique, lived, and embodied experiences.

\section{Reconceptualization of Curriculum}

This online ethnographic study pushes the field to reconceptualize the concept of curriculum as emergent and linked to embodied experiences. In the southwest of the U.S., the presence of individuals of diverse ethnicities and cultures converge in making practices. Rather than prescribed knowledge, curriculum that surrounds making should be deeply rooted into the social and cultural world. Curriculum should aid individuals in making meaning within their life worlds to reflect their existence and identities (Greene, 1975).

Our findings suggest that curriculum should not be viewed as a set of text-based instructions, but instead as rich dialogues about peoples' inquiry, knowledge, experiences, and practices that connect learners with their communities (Marshall, 2011). Magrini (2015) suggests that curriculum is not an extension of learning but instead lives as an embodiment of the human being. A curriculum becomes alive in the ways it flexes and relaxes, ebbs, and flows in sympathetic response to the learning experience grounded in the lived experiences of learners in a community. When viewed in this way, curricula are not fixed but are always in a state of change, just much as the people who create it. This idea of "Lived Curricula" provides space for increased legitimacy to the experiences of localized social and cultural contexts. In this way curriculum relates to the critical relationality tenet of co-construction and aligns to what 
Aoki (2005) refers to as situational praxis. This study encourages the field to reconceptualize curriculum as an interconnected community dynamic that values experience, which is complex and constantly evolving (Powell \& Lajevic, 2011).

\section{Revealing Connections Between Making and Curriculum}

Using a Critical Relationality lens, we contend that not only making curricula, but all curricula should honor community practices, knowledge, values, and people based on the principles of equity and inclusion (Olivares \& Tucker-Raymond, 2020). This same sentiment is acknowledged by the international organizations. UNESCO views curriculum as dynamic synergies created through creative learning processes, rather than a set of documents which describe and prescribe content and outcomes. Curriculum viewed in this way should address epistemic and significant issues as legitimate knowledge and draw on what is meaningful for our lives and society (UNESCO- IBE, 2013).

This viewpoint helps us to see the significance of making and curriculum by considering that knowledge that exists in the community, social and cultural context, and individuals lived experiences. Knowledge that is created by the people, and that emerges from the community, is relevant for inclusion in a curriculum. When a curriculum is defined by community activities, people, and organizations, the curriculum consists of authentic learning experiences and human centeredness that are meaningful and co-constructed by people and communities.

The curriculum materializes as the result of an interplay among its members, their history and cultures, and the world around them. Therefore, curricula for making includes both making processes and community purposes such as, making as a connection, as service to the community and peace making. For instance, BICAS, the bicycle makerspace, makes a connection between STEAM and multidisciplinary groups of people of all ages, gender identities, and orientations who come together to make artifacts, and have experiences that fulfill their life needs. Iskashitaa refugee network provides a space for making that is directly related to Tucson's food sustainability efforts. It is a space where meaning-making revolves around people sharing produce preservation techniques and knowledge and skills with the community. The Muslim Community Center's making practices revolve around peace making with different faith groups.

The findings of this study assert that a maker does not refer to a person who makes in a fancy digitally equipped makerspace. Instead, a maker can be anybody who engages in making in the community, whether the making event is short-lived or long term. Makers include everyone, all those who are historically marginalized (e.g., graffiti artists). They bring valuable expertise and knowledges and embody the community practices.

People continually embody, create, produce, and perform knowledge in relation to their specific context and materials (Powell \& Lajevic, 2011). Embodied curriculum emphasizes people's lived experiences, knowledge, reality, and surroundings. Organizations in the Tucson community construct and reconstruct their own knowledge and negotiate meaning to reflect 
what life and learning is about, and how it is experienced. These facets constitute vital aspects of living curricula (Christodoulou, 2010). When viewed in this way, the curriculum becomes liberated since it is open, dynamic, flexible, and always evolving. Making encourages vitality and transformation through multiple ways of participating and belonging. Curriculum and making are human experiences that are essential our lives, families, cultures, and manifested in our goals, hopes and dreams. Making artifacts represent a community's shared humanity and create opportunities for dialogue.

This study illustrated important forms of learning that happen in the community as the result of creativity and inquiry. This study encourages a reconceptualization of the concepts of making and curriculum. We contend that it is necessary to conduct similar ethnographic studies of community organizations and their making practices to inform the development of curriculum efforts. Such efforts should reflect the community, its people, its history, and its needs, which is contextually specific to each geographic location. Knowledge emerges from the community and this knowledge should in turn serve the community.

\section{Acknowledgement}

The authors wish to acknowledge and show appreciation to the Indigenous Peoples, Tohono O'odham Nation and the Pascua Yaqui Tribe who have stewarded the land where the University of Arizona resides and where our paths have crossed. We extend our greatest gratitude to the Jewell M. Lewis endowment and the Second Language Acquisition and Teaching (SLAT) program for the generous support for funding graduate associate scholarships. Our work would not have been possible without the efforts of the community organizations who opened their hearts to us. This collaboration has given us the opportunity to work, grow, and develop strong and beautiful relationships as colleagues and friends that will last forever. We thank our insightful colleagues Maria Olivares, Eli Tucker-Raymond, Edna Tan, and Cynthia Graville, from the Critical Making and Research Coordination Network, for always inspiring us and being eager to share their extensive knowledge and unparalleled support and encouragement.

\section{REFERENCES}

Aoki, T. (2005). Curriculum in a new key. Lawrence Erlbaum

Bevan, B., Gutwill, J, P., Petrich, M., \& Wilkinson, K. (2015). Learning through STEM-rich tinkering: findings from a jointly negotiated research project taken up in practice. Science Education, 99(1), 98-120.

Bevan, B., Ryoo, J., \& Shea, M. (2017). What if? Building creative cultures for STEM making and learning. Afterschool Matters, 25, 1-8.

Blikstein, P., Kabayadondo, Z., Martin, A., \& Fields, D. (2017). An assessment instrument of technological literacies in makerspaces and FabLabs. Journal of Engineering Education, 106(1), 149-175. 
Bowen, T. (2013). Graffiti as spatializing practice and performance. Rhizomes, 25 (25).

Retrieved May 12, 2021, from http://www.rhizomes.net/issue25/bowen/

Braun, V., \& Clarke, V. (2006). Using thematic analysis in psychology. Qualitative research in psychology, 3(2), 77-101.

Castek, J., Schira Hagerman, M., and Woodard, R. (Eds). (2019). Principles for equity-centered design of STEAM learning-through-making. Tucson: University of Arizona. Retrieved May 12, 2021, from https://circlcenter.org/events/synthesis-design-workshops

Christodoulou, N. (2010). Embodied curriculum. In C. Kridel (Ed.), Encyclopedia of curriculum studies (pp. 332-332). SAGE Publications Inc, https://www.doi.org/10.4135/9781412958806.n184

de Peuter, J. (1998). The dialogics of narrative identity. In M. M. Bell, \& M. Gardiner (Eds.), Bakhtin and the human sciences: No last words (pp. 30-48). SAGE Publications Ltd, https://www.doi.org/10.4135/9781446278949.n3

Freire, P. (1970). The adult literacy process as cultural action for freedom. Harvard Educational Review, 40, 205-225.

Geertz, C. (1973). The interpretation of cultures: Selected essays (ACLS Humanities E-Book). Basic Books.

Gerber, H., Abrams, S., Curwood, J. \& Magnifico, A. (2017). What analytical approaches are available for data analysis?. In Conducting qualitative research of learning in online spaces (pp. 110-137). SAGE Publications Inc, https://www.doi.org/10.4135/9781483398617.

González, N., Moll, L. C., \& Amanti, C. (2005). Funds of knowledge: Theorizing practices in households, communities, and classrooms. Lawrence Erlbaum Associates Publishers. Greene, M. (1975). Curriculum and consciousness. In W. F. Pinar (Ed.), Curriculum theorizing: The reconceptualists (pp. 299-317). McCuthan.

Green, T. L. (2017). From positivism to critical theory: school-community relations toward community equity literacy. International Journal of Qualitative Studies in Education, 30(4), 370-387. http://doi.org/10.1080/09518398.2016.1253892

Hagerman, M. S., Cotnam-Kappel, M., Turner, J. A., \& Hughes, J. M. (2019, April). Layers of online reading, research and multimodal synthesis practices while making: A descriptive study of three fifth-grade students [Roundtable paper presentation]. In American Educational Research Association Annual Meeting (AERA), Toronto, ON, Canada.

Halverson, E. R., \& Sheridan, K. (2014). The maker movement in education. Harvard Educational Review, 84(4), 495-504.

Hine, C. (2000). Virtual ethnography. SAGE.

Hine, C. (2008). Virtual ethnography: modes, varieties, affordances. In N. Fieldings, R. M. Lee \& G. Blank (Eds.), The SAGE handbook of online research methods (pp. 257-270). SAGE Publications Ltd, https://www.doi.org/10.4135/9780857020055 
Hira, A., \& Hynes, M. M. (2016, June), Impromptu reflection as a means for self-assessment of design thinking skills. Paper presented at 2016 ASEE Annual Conference \& Exposition, New Orleans, Louisiana. 10.18260/p.27311

Hynes, M, \& Hynes, W. (2018). If you build it, will they come? Student preferences for Makerspace environments in higher education. International Journal of Technology and Design Education, 28(3), 867-883.

Iskashitaa Refugee Network (n.d.) Who we Serve. Retrieved May 12, 2021, from https://www.iskashitaa.org/who-we-serve

Kafai, Y., Fields, D., \& Searle, K. (2014). Electronic textiles as disruptive designs: Supporting and challenging maker activities in schools. Harvard Educational Review, 84(4), 532-556.

Keune, A., \& Peppler, K. (2017). Maker portfolios as learning and community-building tools inside and outside makerspaces. In B.K. Smith, M. Borge, E. Mercier, K. Lim (Eds.), Making a difference: Prioritizing equity and Access in CSCL: The International Conference on Computer Supported Collaborative Learning (CSCL), Vol. 2, 978-09903550-2-1, International Society of the Learning Sciences, (pp. 545-548), Pittsburgh, PA.

Keune, A., \& Peppler, K. (2019). Materials-to-develop-with: The making of a makerspace. British Journal of Educational Technology, 50(1), 280-293.

Labbo, L.D. \& Reinking, D. (1999). Negotiating the multiple realities for technology in literacy research and instruction, Reading Research Quarterly, 32(4), 478-492.

Ladson-Billings, G., \& Tate, W. (1995). Toward a critical race theory of education. Teachers College Record. 97. 47-68.

Loyd, J. (2012). Human rights zone: Building an antiracist city in Tucson, Arizona. ACME: An International Journal for Critical Geographies, 11(1), 133-144. Retrieved May 12, 2021, from https://www.acme-journal.org/index.php/acme/article/view/923

Magrini, J.M. (2015) Phenomenology and curriculum implementation: discerning a living curriculum through the analysis of Ted Aoki's situational praxis, Journal of Curriculum Studies, 47(2), 274-299, DOI: 10.1080/00220272.2014.1002113

Marshall, S. (2011, June). A living curricula: Conversations about learning and teaching. Paper presented at the Canadian Association for University Continuing Education Conference, Toronto. Retrieved May 12, 2021, from http://www.cauce-conference.ca/2011/wpcontent/uploads/2012/01/The-Living-Curriculum-Steve-Marshall-Cause-2011.pdf

Martin, L. (2015). The promise of the maker movement for education. Journal of Pre-College Engineering Education Research, 5(1), 30-39. doi: doi:10.7771/2157-9288.1099

Martin, F., \& Pirbhai-Illich, F. (2016). Towards decolonizing teacher education: Criticality, relationality and intercultural understanding. Journal of Intercultural Studies. 37. 355372. 10.1080/07256868.2016.1190697 
Martin, L., Dixon, C., \& Betser, S. (2018). Iterative design toward equity: Youth repertoires of practice in a high school maker space, Equity \& Excellence in Education, 51(1), 36-47, DOI: 10.1080/10665684.2018.1436997

Merriam, S. B. (2009). Qualitative research: A guide to design and implementation. (2nd ed.). Jossey-Bass.

Moriwaki, K., Brucker-Cohen, J., Campbell, L., Saavedra, J., Stark, L., \& Taylor, L. (2012). Scrapyard Challenge Jr., Adapting an art and design workshop to support STEM to STEAM learning experiences. Paper presented at the integrated STEM education conference (ISEC), 2012 IEEE 2nd.

Muslim Community Center. (n.d). Home[Website]. Retrieved March 1, 2021, from http://www.mcctucson.org

Muslim Community Center. (n.d.). Home[Facebook page]. Facebook. Retrieved May 14, 2021, from https://www.facebook.com/Muslim-Community-Center-MCC-144124968953648/

Muslim Community Center of Tucson (2019, November 8). Twenty-fifth annual fall festival [Image attached]. Facebook.

https://www.facebook.com/MuslimCommunityCenterOfTucson/photos/a.2789220556 $22870 / 1411257612389303$

Muslim Community Center of Tucson (2019, December 18). Family cultural and game night [Image attached]. Facebook.

https://www.facebook.com/MuslimCommunityCenterOfTucson/photos/a.1721382096 34589/1452077928307271/?type=3\&theater

Office of the High Commissioner for Human Rights (OHCHR, n.d.). OHCHR and the right to food. Retrieved February 26, 2021, https://www.ohchr.org/En/Issues/ESCR/Pages/food.aspx.

Olivares. M. \& Tucker-Raymond, E. (2020). Critical relationality: A justice-oriented approach to education and education research. Medium. Retrieved February 23, 2021

https://medium.com/@mariaco_87227/critical-relationality-a-justice-orientedapproach-to-education-and-education-research-8bf911c381b4.

O'Loughlin, M. (2006). Embodiment and education: Exploring creatural existence. Springer.10.1007/1-4020-4588-3

Open Space Church (2018). Art. https://www.openspacetucson.com/graffiti-and-art

Powell, K., \& Lajevic, L. (2011). Emergent places in preservice art teaching: Lived curriculum, relationality, and embodied knowledge. Studies in Art Education, 53(1), 35-52. https://doi.org/10.1080/00393541.2011.11518851

Sandoval,W. A. (2005). Understanding students' practical epistemologies and their influence on learning through inquiry, Science Education, 89, 634-656

Schlegel, R. J., Chu, S. L., Chen, K., Deuermeyer, E., Christy, A. G., \& Quek, F. (2019). Making in the classroom: Longitudinal evidence of increases in self-efficacy and STEM possible selves over time. Computers \& Education, 142, 103615-103637. 
Sheridan, K. M., Halverson, E. R, Litts, B. K., Brahms, L, Jacobs-Priebe, L, \& Owens, T. (2014). Learning in the making: A comparative case study of three makerspaces. Harvard Educational Review, 84(4), 505-531.

Shotter, J. (1993). Cultural politics of everyday life: Social constructionism, rhetoric and knowing of the third kind. University of Toronto Press.

Southern Arizona Arts \& Cultural Alliance (SAACA). (n.d.). About catalyst. Retrieved May 14, 2021, https://www.tucsonmall.com/en/directory/catalyst-36157.html

Subero, D., Vujasinović, E. \& Esteban-Guitart, M. (2017) Mobilising funds of identity in and out of school, Cambridge Journal of Education, 47:2, 247-263.

Tan, E., \& Calabrese Barton, A. (2018). Towards critical justice: Exploring intersectionality in community-based STEM-rich making with youth from non-dominant communities. Equity \& Excellence in Education, 51 (1), 48-61, DOI: 10.1080/10665684.2018.1439786.

Tucker-Raymond, E., \& Gravel, B. E. (2019). STEM literacies in makerspaces: Implications for learning, teaching, and research. Routledge.

Tucson Interfaith Packathon. (2018. January 2). Tucson interfaith packathon[Image attached]. Facebook. https://www.facebook.com/InterfaithPackathon/

UNESCO International Bureau of Education (UNESCO-IBE). (2013). Training tools for curriculum development - A resource pack. Retrieved May 12, 2021, from:

http://www.ibe.unesco.org/fileadmin/user_upload/Publications/Training_tools/IBECRP-2014_eng.pdf

Vélez-Ibáñez, C., \& Greenberg, J. (1992). Formation and transformation of funds of knowledge among U.S.-Mexican households. Anthropology \& Education Quarterly, 23(4), 313-335. Retrieved February 24, 2021, from http://www.jstor.org/stable/3195869

Vossoughi, S., \& Bevan, B. (2014). Making and tinkering: A review of the literature.

Commissioned paper for successful Out-of-School STEM Learning: A Consensus Study, Board on Science Education, National Research Council. Retrieved from http://sites.nationalacademies.org/cs/groups/dbassesite/documents/webpage/dbasse _089888.pdf

Vossoughi, S., Escudé, M., Kong, F., \& Hooper, P. (2013). Tinkering, learning \& equity in the after-school setting. Paper presented in the annual FabLearn conference. Palo Alto, CA: Stanford University.

Vossoughi, S., Hooper, P. K., \& Escudé, M. (2016). Making through the lens of culture and power: Toward transformative visions for educational equity. Harvard Educational Review, 86, 206-232. https://doi.org/10.17763/0017-8055.86.2.206

Walan, S. (2021). The dream performance-a case study of young girls' development of interest in STEM and 21st century skills, when activities in a makerspace were combined with drama. Research in Science \& Technological Education, 39(1), 23-43. 
Wohlwend, K. E., Peppler, K. A., Keune, A., \& Thompson, N. (2017). Making sense and nonsense: Comparing mediated discourse and agential realist approaches to materiality in a preschool makerspace. Journal of Early Childhood Literacy, 17(3), 444-462.

Xerocraft. (n.d.). Home[Facebook page]. Facebook. Retrieved February 23, 2021, from https://www.facebook.com/Xerocraft/ 